\title{
Lateral heterogeneity in lithospheric structure in SE Tibet
}

\author{
Anne Meltzer*, Brian Zurek, Stephane Sol and Lucy Brown \\ Department of Earth and Environmental Sciences, Lehigh University, Bethlehem, PA 18015, USA

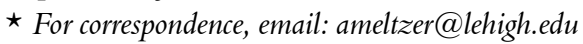

Southeastern Tibet hosts the termination of the Himalayan orogen in the Eastern Himalayan Syntaxis and a transition between the geodynamic setting of the main Plateau, its eastern margin, and the lithosphere of southeast Asia. The Eastern Himalayan Syntaxis occupies a substantial portion of the diffuse India-Asia collision zone, and because it serves as the watershed for the largest rivers in Asia, its highly active tectonic and surface processes have a direct impact on over one billion people. The syntaxis is a crustal manifestation of the complex lithospheric dynamics associated with the Indian "indentor corner." Steep lateral surface velocity gradients and a laterally heterogeneous lithospheric structure mark the northeastern margin of the Indian plate. Such corners are also sites of significant accommodation of crustal convergence by erosion and fluvial evacuation. Within the core of the syntaxis, the Yarlung-Tsangpo River exits the Tibetan Plateau dropping $\sim 2 \mathrm{~km}$ in elevation along an $\sim 100 \mathrm{~km}$ section of the river cross cutting the Namche BarwaGyala Peri massif. This metamorphic massif is the site of high relief, high topography, and rapid recent ongoing exhumation exposing mid to lower crustal rocks of the Indian plate at the surface. Analysis of data recorded by a temporary seismic array document substantial lateral heterogeneity in lithospheric structure and rheology across southeastern Tibet. To first order, observed heterogeneity correlates to surface topography indicating that tectonic and surficial processes interact to shape the evolution of the orogen.

In southeastern Tibet, the fast directions of seismic anisotropy in the lithospheric mantle correlate with surficial geology including major sutures and shear zones, extensional rifts, and with the surface strain derived from the GPS velocity field. These observations are consistent with a clockwise rotation of material around the eastern Himalayan syntaxis and suggest coherent and distributed lithospheric deformation beneath much of southeastern Tibet. The presence of small-scale and regional lateral variations in seismic anisotropy is observed within individual tectonic domains such as the Lhasa terrane and across major sutures and tectonic blocks. In the Lhasa terrane, we observe a change in the orientation of the fast axis of shear-wave polarization suggesting a change in the mode of deformation from orogen perpendicular extension in central Tibet to orogen parallel strike-slip in the eastern syntaxis. Shear-wave splitting measurements also show lateral variations in seismic anisotropy across the Tsangpo and the Bangong sutures indicating that these sutures separate lithospheric domains with distinct rheological properties or deformation regimes.

Detailed 3-d receiver function analysis documents a dramatic change in crustal thickness, Poisson's ratio, and lower crustal reflectivity across the transition from the central Tibetan plateau to the eastern syntaxis. Crustal thickness beneath the southeastern Tibetan plateau varies between 65 to $75 \mathrm{~km}$ but thins eastward beneath the eastern margin of the plateau to $42-$ $50 \mathrm{~km}$. Regionally Poisson's ratio is low $(0.24-0.25)$ where the crust is thick and tends to increase $(0.26-0.29)$ where the crust is thinner. Inversion for velocity structure and geometry using finite difference wave-form inversion indicates a high velocity ( 7.5 to $7.8 \mathrm{~km} / \mathrm{s}$ ) layer near the base of the crust extends north of the Tsangpo suture beneath the southern Lhasa block and terminates just west of the Namche Barwa - Gyala Peri massif. Modeled Pwave velocities for this layer are consistent with eclogite. Further east, an asymmetric anticlinal fold on the crust-mantle boundary is associated with the Namche-Barwa/Gyala Peri metamorphic massif. The asymmetric fold trends north south and is $\sim 50 \mathrm{~km}$ wide with an $\sim 10 \mathrm{~km}$ near vertical step in the Moho on its eastern side. The fold on the crust-mantle interface correlates with a region of high topography and rapid recent exhumation on the surface. Locally higher values of Poisson's ratio (0.26-0.29) exist in this region suggesting a change in average crustal composition, and/or areas with some partial melt.

The eastern syntaxis is seismically active with over 3800 regional and local events $(M>1.4)$ located during a 15-month window. Seismicity is unevenly distributed. A significant number of events locate within the northern margin of the Namche Barwa - Gyala Peri massif. While these events locate at a range of depths in the upper $20 \mathrm{~km}$ of the crust, a significant number of events locate above sea level. These events tend to have extensional focal mechanisms consistent with the release of topographic stress where the Tsangpo and Po-Tsangpo rivers generate dramatic relief. Seismicity is also associated with portions of the Himalayan front, linear river valleys, the Gulu rift, the Nari Yun Chu (or Cona-Qusum) rift, and the Burmese arc. Seismicity is more evenly distributed in the Qiangtang terrane in contrast to the Lhasa terrane which contains several relatively aseismic regions. A portion of the Himalayan front in this region is also relatively aseismic. Most of the seismicity within the plateau appears to be concentrated in the upper $20 \mathrm{~km}$ of the crust but a modest number of events locate in the lower crust and upper mantle.

To first order, lateral heterogeneities in structure and rheology at depth correlate with the transition from the high elevation low relief plateau in central Tibet to deeply incised linear valleys in southeastern Tibet. Our observations suggest that lateral heterogeneities play an important role in the geodynamic evolution of the region. 